\title{
Evaluation of FAO-56 procedures for estimating reference evapotranspiration using missing climatic data for a Brazilian tropical savanna
}

\author{
Luiz Claudio Valle Junior ${ }^{1}$, George Vourlitis ${ }^{2}$, Leone Francisco Curado ${ }^{3}$, Rafael Palacios ${ }^{4}$, \\ José Nogueira ${ }^{3}$, Francisco Lobo ${ }^{3}$, Abu Reza Md. Towfiqul Islam ${ }^{5}$, and Thiago Rodrigues ${ }^{1}$ \\ ${ }^{1}$ Universidade Federal de Mato Grosso do Sul \\ ${ }^{2}$ California State University San Marcos \\ ${ }^{3}$ Universidade Federal de Mato Grosso \\ ${ }^{4}$ Universidade Federal do Para \\ ${ }^{5}$ Begum Rokeya University
}

May 11, 2021

\begin{abstract}
Since the Brazilian Cerrado has been heavily impacted by agricultural activities over the last four to five decades, reference evapotranspiration (ETo) plays a pivotal role in water resources management for irrigation agriculture. The Penman-Monteith $(\mathrm{PM})$ is one of the most accepted models for ETo estimation, but it requires many inputs that are not commonly available. Therefore, assessing the FAO guidelines to compute ETo when meteorological data are missing could lead to a better understanding of how climatic variables are related to water requirements and atmospheric demands for a grass-mixed savanna region and which variable impacts the estimates the most. In this study, ETo was computed from April 2010 to August 2019. We tested twelve different scenarios considering radiation, relative humidity, and/or wind speed as missing climatic data using guidelines given by FAO. When wind speed and/or relative humidity data were the only missing data, the PM method showed the lowest errors in the ETo estimates and correlation coefficient (r) and Willmott's index of agreement (d) values close to 1.0. When radiation data were missing, computed ETo was overestimated compared to the benchmark. FAO procedures to estimate the net radiation presented good results during the wet season; however, during the dry season, their results were overestimated, especially because the method could not estimate negative Rn. Therefore, we can infer that radiation data have the highest impact on ETo for our study area and also regions with similar conditions and FAO guidelines are not suitable when radiation data are missing.
\end{abstract}

\section{Hosted file}

Manuscript (4).pdf available at https://authorea.com/users/317005/articles/521595-evaluationof-fao-56-procedures-for-estimating-reference-evapotranspiration-using-missing-climaticdata-for-a-brazilian-tropical-savanna 


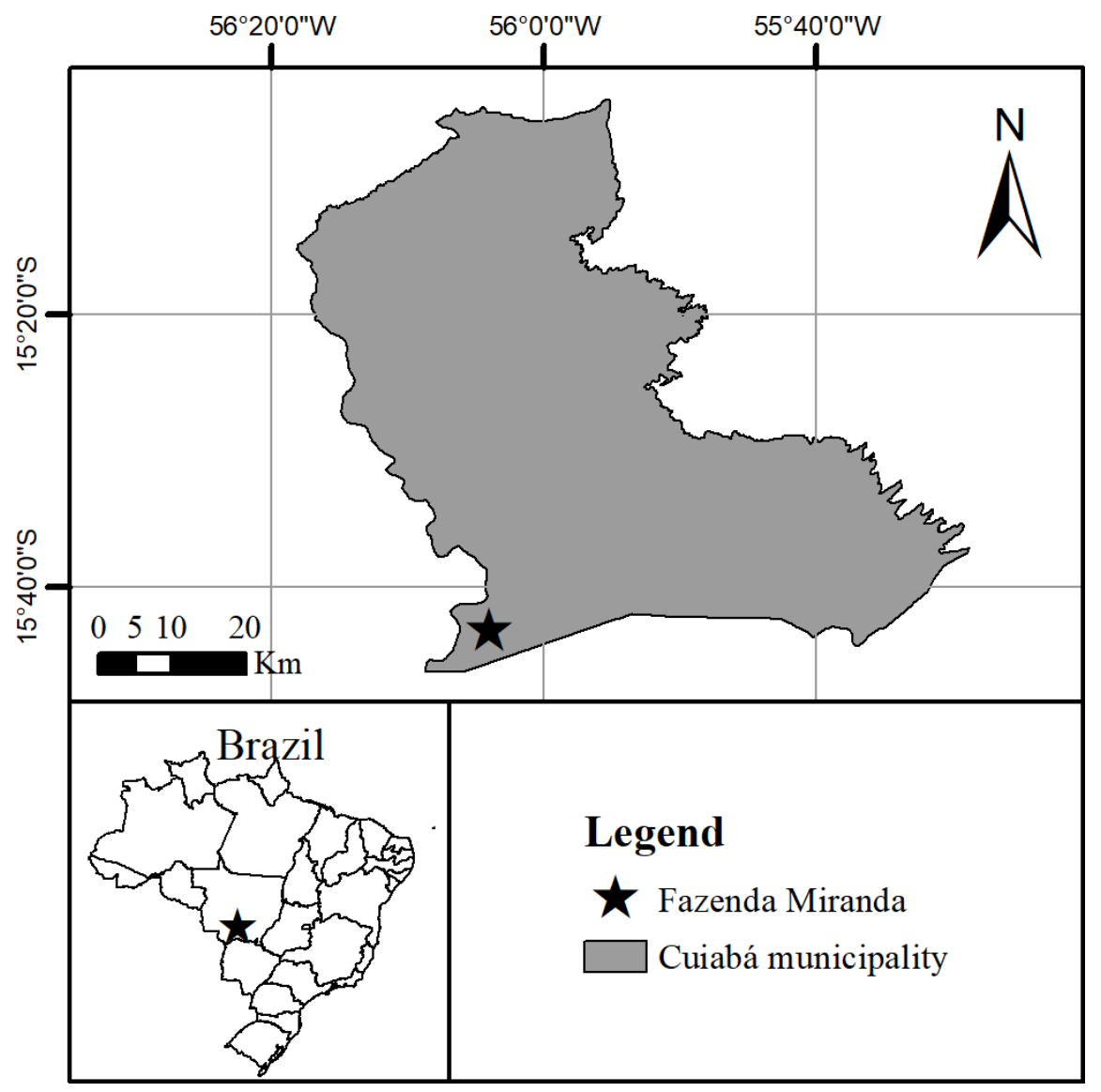



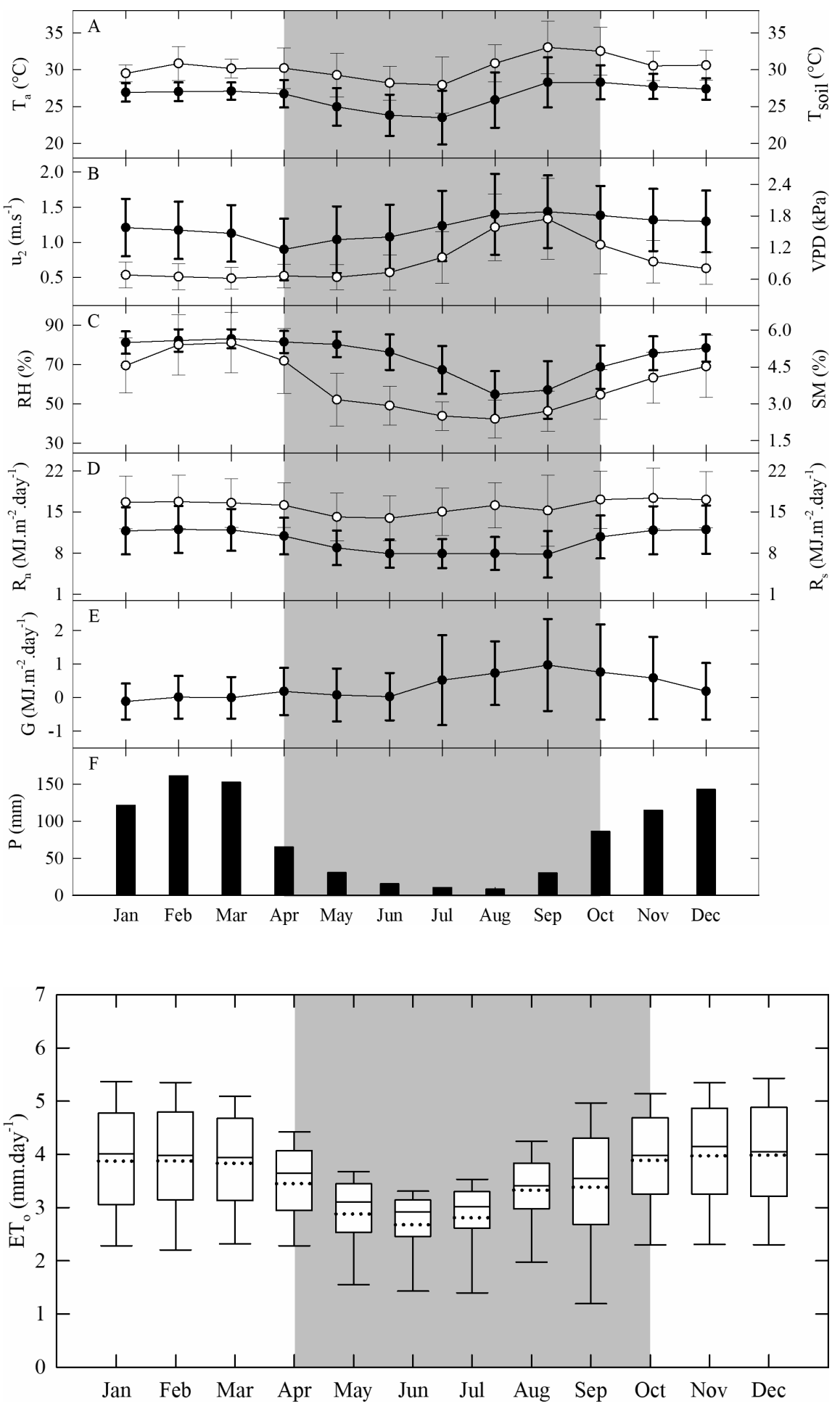

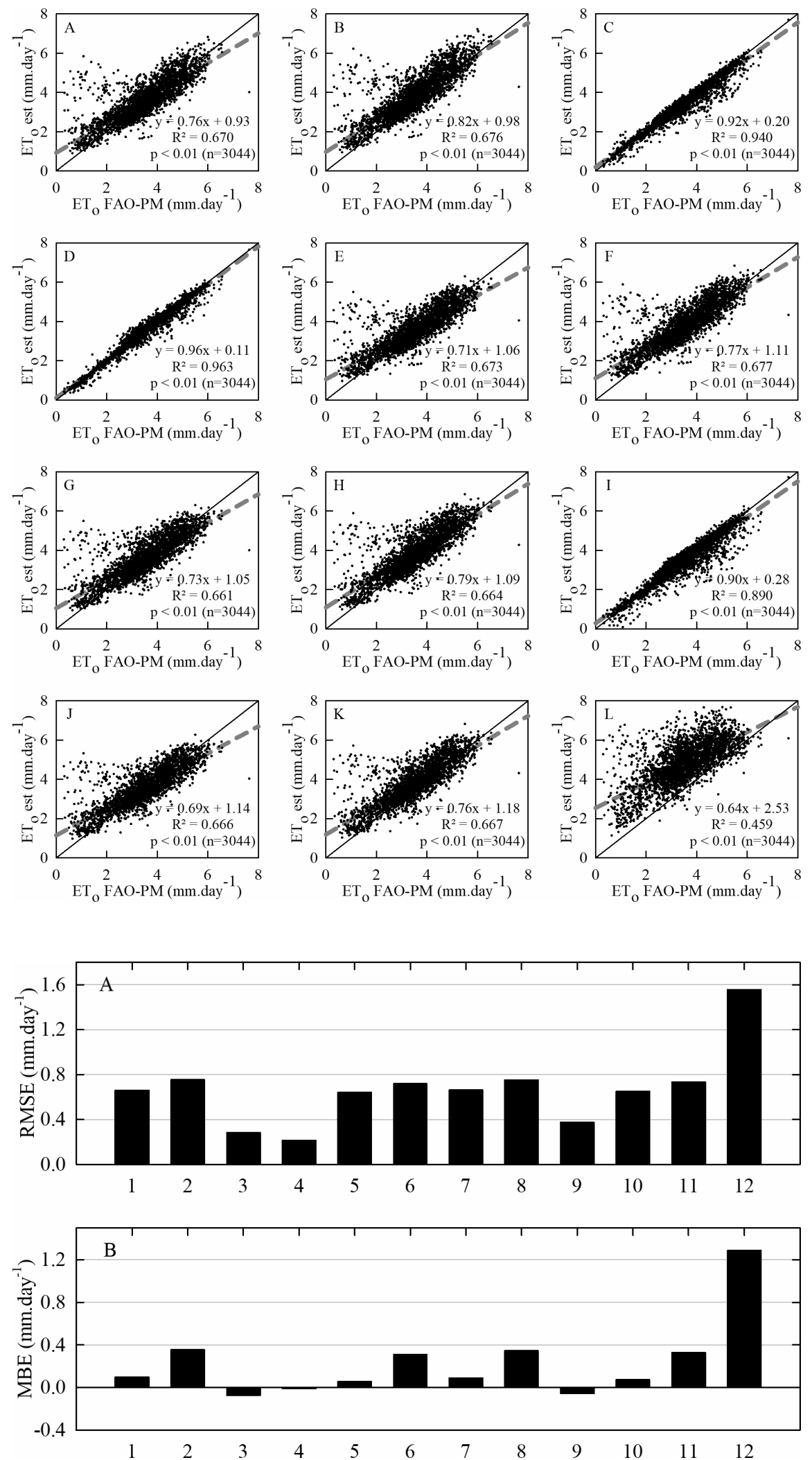

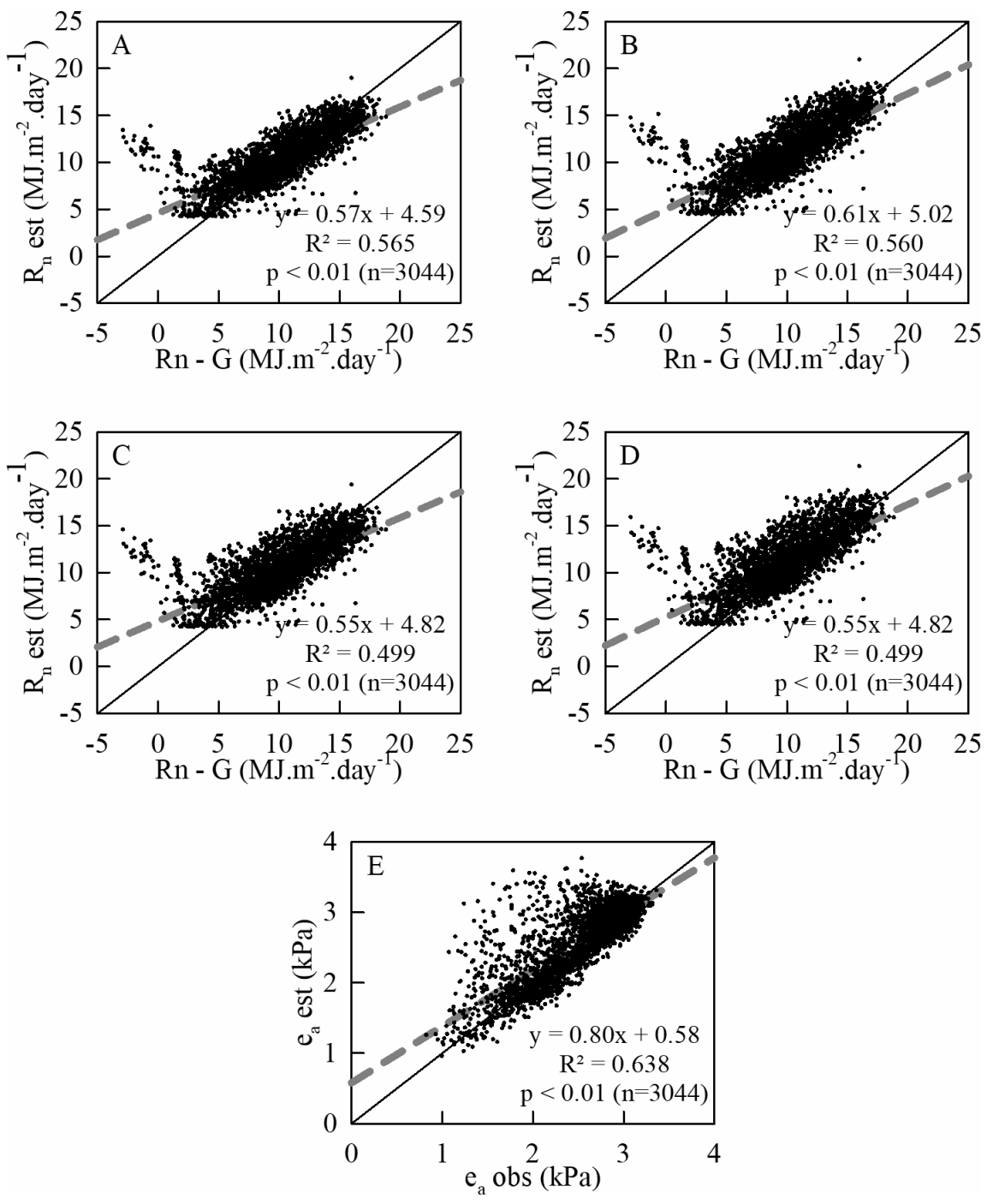

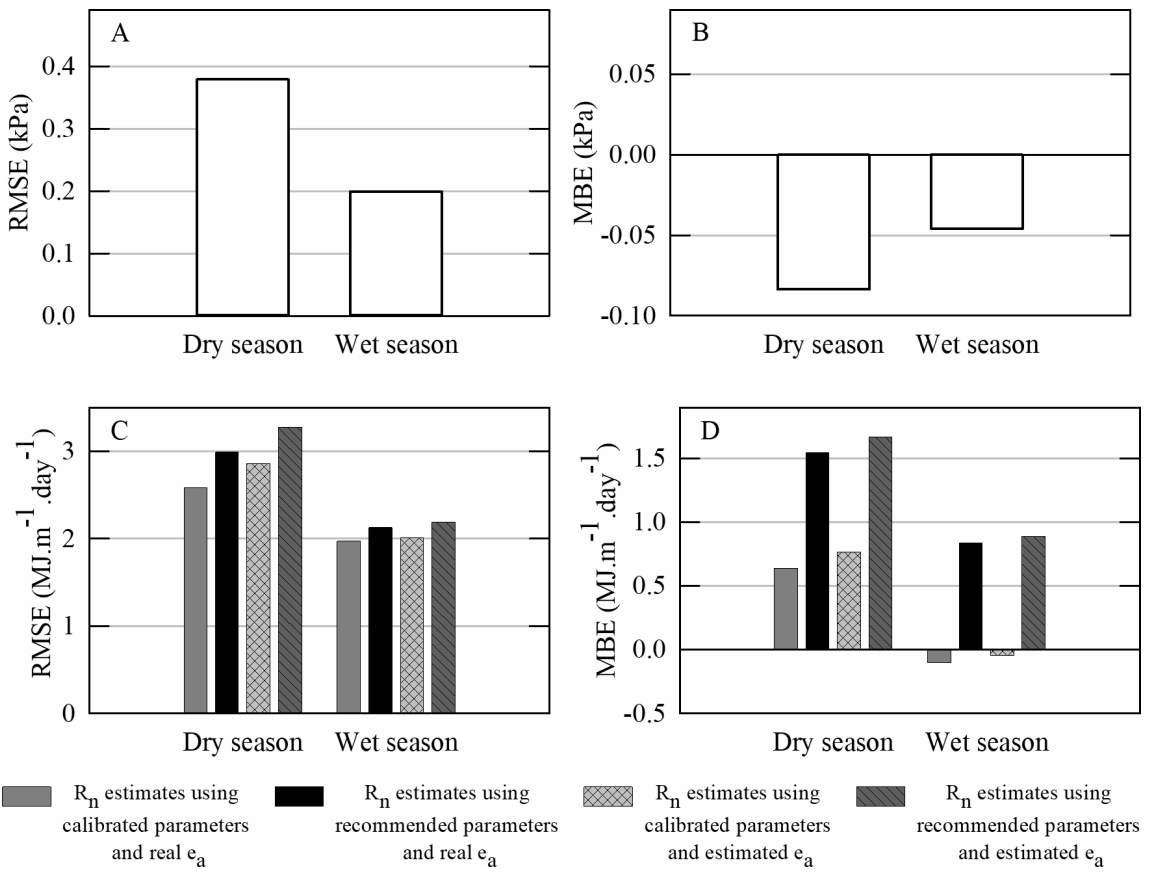

\section{Hosted file}

Table 1 (2).pdf available at https://authorea.com/users/317005/articles/521595-evaluationof-fao-56-procedures-for-estimating-reference-evapotranspiration-using-missing-climaticdata-for-a-brazilian-tropical-savanna

\section{Hosted file}

Table 2 (2).pdf available at https://authorea.com/users/317005/articles/521595-evaluationof-fao-56-procedures-for-estimating-reference-evapotranspiration-using-missing-climaticdata-for-a-brazilian-tropical-savanna 